\title{
Notas sobre os Instrumentos Científicos em Galileu
}

[Notes on Scientific Instruments in Galileo]

\section{Cristiano Novaes de Rezendeף}

Resumo: Na primeira parte deste artigo, procuramos caracterizar o conceito de instrumentalismo a partir dos problemas astronômicos, políticos e teológicos que levaram à contraposição desse programa epistemológico - que limita a ciência ao trabalho de "salvar as aparências" - à concepção de ciência que culminou na Revolução científica dos séculos XVI e XVII. Na segunda parte, mostramos que há certa concepção do conhecimento matemático que se alinha com o instrumentalismo, mas que também há uma outra concepção, sustentada por Galileu, que considera a matemática como expressão de relações estruturais constitutivas da própria realidade física. $\mathrm{Na}$ terceira parte, defendemos que, contra a ideia de instrumento contida no programa instrumentalista, Galileu entende seus instrumentos científicos como teorias em estado concreto e operante. Para demonstrar isso, examinamos algumas posições de Galileu sobre o uso de alguns instrumentos científicos que ele próprio confeccionou, a saber: o compasso geométrico militar, a balança hidrostática e o telescópio.

Palavras-chave: realismo, instrumentalismo, ciência, teologia, política.

Abstract: In the first part of this paper, we try to characterize the concept of instrumentalism analyzing the astronomical, political and theological problems that led to the contraposition of such epistemological program - that reduces science to the work of "saving appearances" - to the conception of science that culminated with the Scientific Revolution of the sixteenth and seventeenth centuries. In the second part, we show that there is a certain conception of mathematical knowledge that aligns with instrumentalism, but that there is also another conception, supported by Galileo, that considers mathematics as an expression of structural relations constitutive of physical reality itself. In the third part, we defend that, against the idea of instrument contained in the instrumentalist program, Galileo understands his scientific instruments as theories in concrete and operant state. To demonstrate such interpretation, we have examined Galileo's positions on the use of some of the scientific instruments he has made, namely, the military-geometric compass, the hydrostatic scale, and the telescope.

Keywords: realism, instrumentalism, science, theology, politics.

\footnotetext{
${ }^{*}$ Professor da Faculdade de Filosofia da Universidade Federal de Goiás (UFG). Doutor em filosofia pela USP. E-mail: cnrz1972@gmail.com. ORCID: https://orcid.org/0000-0002-4935-629X.
} 


\section{1- Instrumentalismo, Teologia e política}

O caso da condenação de Galileu Galilei pela inquisição romana articula de forma emblemática um problema epistemológico e um problema teológico-político. Uma defesa realista do copernicanismo, como a pretendida por Galileu no Diálogo sobre os dois Máximos Sistemas de Mundo: Ptolomaico e Copernicano, de 1632, exigia uma correlata interpretação não-realista, mas sim metafórica, das passagens da Bíblia que parecem corroborar um sistema planetário geocêntrico e com uma Terra estacionária. No entanto, no contexto da Contra Reforma, onde o modo de interpretar as Sagradas Escrituras dividia católicos e protestantes, a admissão de interpretações do texto bíblico alternativas às autorizadas, como seriam as interpretações metafóricas, era uma questão extremamente delicada. Mormente se lembrarmos que, de ambos os lados, o poder político pretendia-se fundado na autoridade religiosa, a qual, por sua vez, encontrava fundamento nas escrituras e, em última instância, na revelação divina.

Na célebre Carta a Foscarini, de 1615 , isto é, antes da publica- ção do Diálogo e da consequente condenação de Galileu, o Cardeal Belarmino - intelectual orgânico da inquisição romana recomendara aos adeptos do copernicanismo que, por prudência, fizessem o contrário: deixassem a verdade ao encargo da autoridade religiosa e reduzissem o sistema copernicano não propriamente a uma metáfora mas sim a um mero instrumento matemático de reprodução e predição das posições observáveis dos planetas. Belarmino está longe de ser um tolo. Ele reconhece que o sistema copernicano é superior em simplicidade e comodidade no nível dos cálculos, mas também sabe que o realismo tem uma tarefa demonstrativa: precisa primeiro mostrar que a teoria proposta é capaz de reproduzir os fenômenos passados, coincidir com os fenômenos presentes e predizer os fenômenos futuros. Para usar o jargão da época, a tarefa liminar de uma teoria é mostrar-se capaz de "salvar as aparências". Mas isso, embora absolutamente necessário para a verdade, não é suficiente. Leiamos as palavras de Belarmino, nas quais ele aceita, inclusive, que seja dada outra interpretação das passagens bíblicas relevantes, desde que uma verdadeira demonstração 
seja apresentada:

Dizer que se salvam melhor as aparências de acordo com a suposição de a Terra ser móvel e o Sol imóvel, do que supondo os excêntricos e os epiciclos, é falar muito bem - não havendo nenhum perigo nisso e por ser isso suficiente para o matemático. Mas afirmar que na realidade o Sol é imóvel no centro do universo... é arriscar-se não somente a irritar todos os filósofos escolásticos e teólogos, mas também a ofender a Santa Fé, tornando falsas as Sagradas Escrituras. [...] Se existir uma verdadeira demonstração de que o Sol está parado no centro do mundo, de que a Terra está no terceiro céu e de que o Sol não circula em torno da Terra, mas a Terra em torno do Sol, afirmo que deveremos começar a trabalhar com muita ponderação para explicar as Passagens das Escrituras aparentemente contrárias a essa opinião e que deveremos dizer não termos entendido essas passagens, em vez de sustentar ser falso o que foi demonstrado. Contudo, não acreditarei que exista tal demonstração antes que alguém a mostre a mim: pois demonstrar que, supondo o Sol imóvel no centro e a Terra se movendo pelo céu, poderemos salvar as aparências, não é o mesmo que demonstrar que assim é na verdade. Acredito que a primeira demonstração possa ser dada, mas tenho as maiores dúvidas em relação à segunda e, em caso de dúvida, não devemos abandonar a interpretação das Sagradas Escrituras dada pelos Padres da Igreja [...] (BELARMINO apud LOPARIC, 2008, p. 240, itálicos nossos).

Para explicitar plenamente por que salvar as aparências não é o mesmo que demonstrar que assim é na verdade, cabe remeter a expressão ao seu contexto de origem. Ela deriva da crítica de Aristóteles aos arroubos teóricos do pitagorismo (Metafísica, A, 5, 985b 23ss apud KIRK, RAVEN \& SCHFIELD, 1994, p. 347), cujos partícipes, diante de discrepâncias entre a teoria $(\log o s)$ e os dados observacionais (phainomena), conservavam a teoria e mudavam os dados, forjando obje- 
tos exigidos pela teoria mas jamais observados (ou até mesmo jamais observáveis!). Contra isso, o sensato Aristóteles propõe: em caso de discrepância entre a teoria e os fenômenos, "conservar os fenômenos!" (sozein ta phainomena), isto é, literalmente, "salvar as aparências", num uso do verbo "salvar" que significa mais propriamente manter, guardar, conservar. Ora, muitos astrônomos gregos - de Eudoxo e Calipo, no século IV a.C. a Ptolomeu, no século II d.C. - levaram às últimas consequências esse preceito aristotélico. Diante de alguns fenômenos astronômicos tradicionalmente desafiadores, tal como o chamado movimento retrógrado aparente dos planetas ${ }^{1}$, esses astrônomos propuseram artifícios geométricos? , artifícios que eles nunca pretenderam que descrevessem a real estrutura do universo, mas que, ainda assim, eram eficazes justamente em "salvar as aparências". Ou seja, uma teoria assumidamente falsa - no sentido de jamais haver pretendido que esses círculos matemáticos em que os planetas eram colocados durante o cálculo existissem na realidade - pode perfeitamente reproduzir os fenômenos passados, coincidir com os fenômenos presentes e predizer os fenômenos futuros. Logo, fazê-lo não é condição suficiente para afirmar a verdade da teoria, embora não fazêlo seja suficiente para afirmar sua falsidade.

É nesse mesmo espírito que o luterano Andreas Osiander - que supervisionara a publicação do De Revolutionibus Orbium Coelestium, de Copérnico, em 1543 - tentara possivelmente proteger o autor, adicionando a esta obra um prefácio apócrifo com um programa instrumentalista, de matriz protestante, que constituíra, quase um século antes, um precedente até mais radical que o da inquisição romana:

Com efeito, é próprio do astrônomo compor, por meio de uma observação diligente e habilidosa, o registro dos movimentos celestes. E, em seguida, inventar e imaginar as causas dos mesmos, ou melhor, já que não se podem alcançar de modo algum as verdadeiras, quaisquer hipóteses que, uma vez supostas, permitam que esses mesmos

\footnotetext{
${ }^{1}$ O movimento retrógrado corresponde ao fato de que, em dado momento de sua trajetória anual, os planetas parecem 'andar para trás', para depois retomarem o sentido original

2 Por exemplo: o artifício do epiciclo e deferente consistia em colocar o planeta orbitando não diretamente ao redor da Terra mas ao redor de um ponto que, este sim, orbitava ao redor da Terra.
} 
movimentos sejam corretamente calculados, tanto no passado como no futuro, de acordo com os princípios da geometria. Ora, ambas as tarefas foram executadas com excelência pelo autor. Com efeito, não é necessário que essas hipóteses sejam verdadeiras e nem mesmo verossimeis, bastando apenas que forneçam cálculos que concordem com as observações (...) Pois é mais do que patente que essa arte ignora simplesmente e por completo as causas dos movimentos aparentes irregulares. E se inventa algumas na imaginação, como certamente inventa muitas delas, todavia não o faz de modo algum para persuadir quem quer que seja de que assim é, mas tão somente para estabelecer corretamente o cálculo. E como às vezes várias hipóteses se oferecem para um mesmo movimento (...), o astrônomo de preferência tomará aquela cuja compreensão seja a mais fácil. $O$ filósofo talvez exigisse antes a verossimilhança, contudo, nenhum dos dois compreenderá ou transmitirá nada de certo a não ser que lhe seja revelado por Deus. Permitamos, pois, que, junto com as antigas, em nada mais verossímeis, façamse conhecer também essas novas hipóteses, tanto mais por serem elas ao mesmo tempo admiráveis e fáceis, e por trazerem consigo um enorme tesouro de doutíssimas observações. E que ninguém espere da astronomia algo de certo no que concerne a hipóteses, pois nada disso procura ela nos oferecer (OSIANDER, 1980 - itálicos nossos).

É com base nesse prefácio que Belarmino começa sua argumentação na Carta a Foscarini, dizendo que para este último, assim como para Galileu, seria prudente contentar-se em falar "por suposição (ex hypothesi) e não de modo absoluto, como eu sempre cri que tenha falado Copérnico" (em GALILEU, 2009, p. 131 - itálicos nossos). Assim, a manutenção do sistema astronômico heliocêntrico na condição de uma hipótese eficaz, garante que o direito ao discurso robusto sobre como as coisas efetivamente são permaneça - por impossibilidade do contrário (Osiander) ou por prudência (Belarmino) - sob a guarda da religião, direito no qual, em última aná- 
lise, funda-se o poder teológicopolítico. Ora, como se vê, um programa que trata o trabalho científico como a mera elaboração de instrumentos eficazes de reprodução e predição de fenômenos empíricos presta-se, portanto, a operar como correlato epistemológico do fundamentalismo religioso no plano político. Amansado cognitivamente, o copernicanismo poderia ser empregado como sendo apenas uma nova tecnologia de cálculo, mais leve e ágil do que a maquinaria geométrica de Ptolomeu, mas em nada ameaçadora no âmbito do discurso sobre como as coisas realmente são. E - supostamente - nada haveria de vergonhoso nessa deflação epistemológica, nessa redução instrumental, visto que tantos outros do mesmo modo se resignaram.

Nesse sentido, o realismo de Galileu, defendido no Diálogo sobre os dois Máximos Sistemas de Mundo, e responsável por sua derradeira condenação, é a reivindicação do direito ao discurso sobre a realidade, desde fora dos particulares grupos agraciados pela revelação divina ou fundados na autoridade dos mesmos.

\section{2 - Instrumentalismo e Matemá-} tica

Em seu artigo "Descartes e Galileu: copernicanismo e o fundamento metafísico da física", $\mathrm{M}$. Friedman (2011) apresenta um enunciado especialmente claro do realismo de Galileu. Trata-se do seguinte trecho da Primeira Carta sobre as Manchas Solares, de 1612:

os astrônomos filosóficos [são aqueles] que, indo além da exigência de, de alguma forma, salvar as aparências, procuraram investigar a verdadeira constituição do universo - o problema mais importante e admirável que existe. Pois esta constituição existe; ela é única, verdadeira, real e não poderia ser de outra forma. E a grandeza e a nobreza deste problema lhe confere o direito de ser colocado à frente de todas as questões suscetíveis de solução teórica (FRIEDMAN, 2011, p. 82)

Como explica Friedman, nesta carta Galileu distingue os "astrônomos filosóficos" daqueles que o próprio Galileu chama de "astrônomos matemáticos", sendo 
estes últimos os que usam quaisquer instrumentos que possam facilitar seus cálculos. De nossa parte, gostaríamos de notar que, a bem dizer desde os pitagóricos, o que está em questão é o estatuto da relação entre matemática e realidade física. A crítica de Aristóteles aos pitagóricos já era precisamente uma recusa de certo realismo matemático: "os chamados pitagóricos dedicaramse às matemáticas; foram eles os primeiros a fazer progredir estes estudos, e tendo sido criados neles, pensaram que seus princípios eram princípios das coisas (archas tôn ontôn)" (Metafísica, A, 5, 985b 23ss apud KIRK, RAVEN \& SCHFIELD, 1994, p. 347). Osiander, por sua vez, coloca "os princípios da Geometria" sob regime de completa recusa não só da verdade mas até mesmo da verossimilhança, bastando a uma teoria, reduzida à condição de mera hipótese, fornecer cálculos que concordem com as observações. Já Belarmino recomenda muita prudência aos copernicanos, mas isso justamente em razão da profunda diferença que há entre a demonstração "suficiente ao matemático" e a "demonstração verdadeira" . E o próprio Galileu, como se viu, também reconhece tal diferença, defendendo, consequentemente, ao contrário de Osiander, uma astronomia filosófica que, sem dei- xar de salvar as aparências, fosse além disso.

Mas, então, cabe perguntar: se o realismo possui duas tarefas, das quais apenas a primeira é salvar as aparências, qual será a segunda? Isto é, nas palavras de Friedman: "como pode um sistema astronômico ir além de salvar as aparências de modo a capturar ou corresponder à 'verdadeira constituição do Universo'?" (FRIEDMAN, 2011, p. 83). Ora, o modo como o comentador reconstrói a resposta galileana é bastante elucidativo, pois mostra que a concepção de conhecimento matemático sustentada pela tradição científica em que se alinham Galileu, Descartes e Newton é consideravelmente mais forte tanto frente ao instrumentalismo antigo e moderno quanto frente ao contemporâneo método hipotético dedutivo, limitado a cotejar os dados observacionais com as hipóteses teóricas e suas consequências:

Segundo [a concepção galileana], a matemática não apenas poderia ser usada para modelar os fenômenos, como há muito já vinha sendo feito na astronomia tradicional, como poderia também ser empregada progressivamente para analisar as ações das causas dos fenô- 
menos. Quanto a isso, a célebre análise feita por Galileu da queda dos corpos e do movimento dos projéteis foi paradigmática [...] [No caso dos projéteis,] a trajetória parabólica resultante não é obtida somente pela adaptação da curva aos dados observados: ela é matematicamente derivada de uma análise das ações causais relevantes. [...] Visto que nossa descrição propositadamente abstrai de todas as outras ações (atrito, resistência do ar, etc.), este é apenas um primeiro passo da análise. Uma teoria matemática completa irá, portanto, proceder progressivamente à medida que formos capazes de incorporar essas ações causais adicionais [...]. Em consequência, o resultado será muito mais que um modelo entre outros para salvar as aparências [...]. Em vez disso, a interação contínua e progressiva entre análises causais matemáticas e evidências empíricas resultaria, esperava-se, ao final, em um modelo único - que, então, teria o estatuto de uma conclusão matematicamente demons- trada a partir dos fenômenos (FRIEDMAN, 2011, p. 83 - itálicos nossos).

Há, portanto, um uso da matemática que é puramente instrumental e que, como tal, compõese tranquilamente com o fundamentalismo religioso tanto da Reforma quanto da Contra Reforma; mas há também uma outra atitude matemática, de ascendência pitagórica, que encontra-se, ao contrário, afinada com os anseios filosóficos que impulsionaram a Revolução Científica dos séculos XVI e XVII. Ambos os usos da matemática consistem na produção de instrumentos de cálculo. Mas a própria concepção de instrumento aí presente varia, assim como varia o estatuto epistemológico da matemática.

\section{3 - Os Instrumentos científicos construídos por Galileu}

O que há de ser um instrumento científico para Galileu? Certamente não parece equivaler à mesma concepção de instrumento que preside a própria elaboração do conceito de instrumentalismo. Esse termo foi empregado por Karl Popper para designar um dos três pontos de vista sobre o conhecimento humano apresentados em Conjecturas e Refutações (POPPER 
1982 p. 125-246) a propósito das diferentes apreciações que podem ser feitas sobre a ciência de Galileu, embora digam respeito à ciência em geral. A concepção de instrumento que parece ter levado Popper a usar precisamente esse nome para designar uma tal maneira de compreender a ciência é a de um meio de cálculo que, enquanto hipotético, é literalmente sub-posto: posto embaixo e depois — isto é, como um sustentáculo ad hoc - dos fenômenos observados. Um instrumento, na acepção instrumentalista, é algo produzido 'sob encomenda' para funcionar, para salvar os phainomena, custe isso o que custar ao logos. Assim como um homem venal e sem princípios, tal instrumento não tem, por assim dizer, escrúpulos próprios: faz qualquer negócio teórico para sustentar os dados observacionais, numa perfeita inversão dos excessos dos pitagóricos, que faziam qualquer negócio para salvar sua teoria (como forjar, sob encomenda da teoria, realidades inobserváveis). Os únicos princípios a que o instrumentalista obedece são justamente os princípios da matemática (como dizia Osiander). Mas tais princípios não passam disso mesmo, ou seja, de princípios da matemática, sem nenhuma conexão com os princípios que presidem a própria natureza. Portanto, o que ca- racteriza o instrumento evocado pelo instrumentalismo é sua exterioridade, independência e secundariedade frente ao objeto a que ele, portanto, simplesmente se sub-mete. Para o instrumentalismo, o logos devém, assim, um servo invertebrado das evidências empíricas: pode ser usado e abusado, vergado do jeito que for, desde que produza cálculos que concordem com as observações.

Uma crítica desse desrespeito para com o logos pode ser lida numa importante passagem da Carta-Prefácio do próprio Copérnico ao Papa Paulo III, para a edição do De Revolutionibus, e que fora substituída, à revelia de Copérnico, pelo prefácio apócrifo de Osiander:

Assim, não quero esconder de vossa Santidade que nada mais me moveu a pensar a respeito de uma outra maneira de calcular (alia ratione subducendorum) os movimentos das esferas do mundo senão que entendi (intellexi) que os próprios Matemáticos não são consistentes consigo próprios (sibi ipsis non constare) ao investigá-los [sc. tais movimentos]. (...) Também a forma do mundo (mundi formam) e a exata sime- 
tria de suas partes (partium eius certam symmetriam) é a coisa principal (rem prceipuam) que eles não conseguiram encontrar nem inferir (invenire, vel ... colligere) (...). Ao contrário, aconteceu-lhes como se alguém tomasse (sumeret), de diversos lugares (à diversis locis), pés, cabeça, e outros membros, pintados (depicta) até mesmo de maneira perfeita (optime quidem), mas sem comparação com um corpo único (sed non unius corporis comparatione), de modo algum correspondendo reciprocamente entre si (nullatenus invicem sibi respondentibus), de sorte a compor com eles (ex illis componeretur) mais um monstro do que um homem (monstrum potius quàm homo). (COPÉRNICO 2008 pp. 262-263).

Mas, além desse "servil instrumento", meramente acoplado à $\mathrm{Na}$ tureza mesmo que ao preço do esquartejamento da organicidade do logos, parece-nos haver em Galileu, um pensamento do instrumento ativo, no qual se constata uma verdadeira unidade entre o $\operatorname{logos}$ e as operações técnicas de cálculo, sem que estas últimas cor- rompam a dignidade daquele primeiro. Enquanto, por exemplo, $\mathrm{o}$ instrumentalismo reduz as teorias a meros instrumentos não estaria Galileu pensando seus instrumentos como teorias em estado concreto e operante? Procuraremos, a seguir, responder afirmativamente a essa questão, buscando justificar tal resposta através de passagens textuais de Galileu sobre o uso de alguns instrumentos científicos que ele próprio confeccionou, a saber: o compasso geométrico militar, a balança hidrostática e o telescópio.

\section{1 - O Compasso Geométrico- Militar}

Comecemos pelo Compasso geométrico e militar. Tratava-se de algo que "no seu tempo correspondia mais ou menos à régua de cálculo ou à minicalculadora" (THUILLER, 1986, p. 139), ou, nas palavras do próprio Galileu, um instrumento que "em pouquíssimos dias ensina tudo aquilo que da geometria e da aritmética, para uso civil e militar, não sem longuíssimos estudos pelas vias ordinárias, se recebe" (GALILEU, 1649, p. 369). Pode-se com ele, por exemplo, aplicar de diversas maneiras as regras de três; transpor em proporção figuras semelhantes; realizar divisões iguais e de- 
siguais no círculo; extrair as raízes quadrada e cúbica; estabelecer proporções entre pesos de diversos materiais; fazer medidas trigonométricas com a vista, e inúmeras outras operazioni que são explicadas no manual de instruções que ensina o uso do instrumento. E, de fato, o que é mais relevante para o nosso tema é justamente a existência desse manual - talvez um dos primeiros no gênero - e as considerações que, nele, Galileu faz a seu respeito e a respeito do instrumento.

Não é, pois, de pouca relevância que, neste manual de instruções, Galileu se refira ao próprio manual e ao sentido de fazê-lo acompanhar o instrumento: só com isso Galileu já nos dá indícios de que em tal instrumento encarna-se um certo saber - o qual não se limita ao mero manuseio da peça particular, mas, como dito acima, "insegna tutto quello che dalla geometria e dall'aritmetica [...] si riceve" . Eis o que promete, no prefácio do manual, a $i$ discreti lettori: "poder, seja qual for a pessoa, resolver em instantes as mais difíceis operações de aritmética; das frequentemente acontecem" (idem, ibidem).

Se, por um lado, o compasso é um instrumento de cálculo, a necessidade da presença de seu manual, por outro, diz respeito à própria aquisição da geometria, pensada de modo que pudesse ser aprendida por aqueles que, como os militares no campo de batalha, "estando em tantos outros misteres ocupados e distraídos, não podem exercitar nestes aquela assídua paciência, que aí seria necessária" (idem, ibidem). Mas leiamos também, por outro lado, as seguintes palavras de Galileu:

Lamento somente, benigno leitor, que, por mais que eu tenha engenhado em explicar as seguintes coisas com toda a clareza e facilidade possível, todavia, a quem as terá de extrair dos escritos, permanecerão envoltas em alguma obscuridade, perdendo por isso muito daquela graça que, ao vêlas operar atualmente e ao aprendê-las de viva voz, as torna maravilhosas: esta é, porém, uma daquelas matérias que não suportam ser descritas com clareza e facilidade e entendidas se, antes de viva voz não se as auscultam e no ato mesmo não se veem exercitar. E esta teria sido poderosa causa, que me teria feito abster-me de imprimir esta obra..." (GALILEU, 1649, p. 370 - 
itálicos nossos).

Devemos, portanto, com tais palavras reforçar a ideia de que a compreensão que Galileu tem de seu Compasso Geométrico e Militar é tal que, nem o instrumento pode ser usado e atingir seus propósitos sem o manual e toda a geometria - a ser ensinada - que ele contém, nem o manual será suficiente a quem não dispuser do instrumento para vê-lo "operar atualmente". A matemática, aqui, não vêm de fora. Muito pelo contrário: existe de modo concreto como que nas inscrições das linhas feitas no metal desse compasso; a geometria aí presente não é a dos astrônomos gregos instrumentalistas, mas sim a de uma tradição que, assim como se passa nos pitagóricos, considera que os princípios da matemática eram princípios verdadeiros do comportamento das coisas. Nessa tradição inserese também Arquimedes, nominalmente citado por Galileu no manual do compasso como seu inspirador. E com tal referência a Arquimedes, passamos diretamente ao contexto da tradição em que se inscreve aquele outro instrumento de Galileu: a balança hidrostática.

\section{2 - A Balança Hidrostática}

Em La Bilancetta, Galileu (1986, pp. 105-107) pretende resolver, com exatidão, o famoso problema da coroa de Hieron, que aqui descrevemos através das palavras de Pierre Lucie:

Cerca de 250 a.c., Hieron, rei de Siracusa, encomendou uma coroa de ouro a seu ourives. Entregue a coroa, Hieron desconfiou que o ourives o tinha roubado, misturando prata ao ouro. Chamou então Arquimedes e o encarregou de apurar a possível fraude. Arquimedes, de fato, confirmou o roubo, mas o lendário “Heureka!!” é praticamente tudo o que conhecemos do processo utilizado pelo célebre matemático para resolver o problema (LUCIE, 1986, p. 96).

Nesse pequenino texto sobre a construção da balança hidrostática, Galileu afirma que, até seus dias, não se sabia exatamente como teria procedido Arquimedes para descobrir o furto do ourives e a quantidade exata de ouro subtraída e substituída por prata. 
Galileu frisa que - a despeito da informação histórica muito difundida de que Arquimedes teria posto a coroa na água depois de haver mergulhado separadamente ouro puro e prata pura, deduzindo, através das proporções de água deslocada em cada caso, a composição da liga de que a coroa se compunha - isto seria, no entanto, "coisa muito grosseira e longe da perfeição" se tivermos em conta "as mui engenhosas invenções" de Arquimedes (GALILEU, 1986, p. 105). Pierre Lucie mostra, em seu artigo sobre $L a$ Bilancetta (LUCIE, 1986, p. 95), que o paradigma arquimediano permanece em Galileu como base para a geometrização de problemas físicos, de maneira que a referência às "invenções engenhosas" de Arquimedes, feita pelo próprio Galileu, poderia ser um exemplo relevante da maneira específica pela qual este paradigma operava em seu pensamento: para conseguir "a precisão requerida nas coisas matemáticas" (GALILEU, 1986, p. 105) não bastaria, no caso, simplesmente "utilizar a água" - que era "o pouco que [os contemporâneos de Arquime- des] haviam entendido de sua solução do problema". Era preciso, antes, elaborar um instrumento ${ }^{3}$. Contando com um instrumento, Galileu pôde acrescentar, em seu texto, à expressão "por meio da água”, a expressão "de modo rigoroso".

É conhecido de toda a tradição interpretativa focada na revolução científica dos séculos XVI e XVII o texto de Aristóteles, na Ética a Nicômaco, em que ele diz que "a precisão não deve ser procurada igualmente em todas as discussões, como não deve ser procurada, por exemplo, na demiurgia" (ARISTÓTELES, 1948, 1094b e ss). Ora, tomando a falta de rigor e precisão do procedimento vulgarmente considerado o de Arquimedes no caso da coroa de $\mathrm{Hi}$ eron como sendo a principal motivação para a construção de sua balança hidrostática, Galileu está rompendo com essa tradição aristotélica que separa poiésis (produção, saber fazer com que algo venha a ser) e epistéme (ciência, conhecimento do necessário). Destarte, Galileu - como no caso do compasso geométrico e militar sugerindo novamente que a exati-

\footnotetext{
${ }^{3}$ Cf. Clavelin (1986 p. 39), onde se demonstra que, se é verdade que Galileu não dispunha de todos os conceitos e pressupostos dos quais depende o método experimental moderno, não é menos verdade, porém, que nele há "um método determinado - ou, se preferirmos, uma visão coerente e estável das condições que uma teoria ou modelo explicativo devem satisfazer para serem considerados verdadeiros, intrinsecamente conformes à realidade". De nossa parte, pretendemos apenas propor que a construção do instrumento parece ser um dos pontos centrais desse método.
} 
dão do procedimento depende de um uso apropriado dos elementos materiais e de uma consequente produção de instrumentos, mas também, em contrapartida, de um conhecimento teórico, nos conta que reviu "cuidadosamente os tratados de Arquimedes" (GALILEU, 1986, p. 105), e, assim, adverte que "o método [para resolver o problema] procede por meio de uma balança cuja construção e uso serão expostos depois que se tenha explicado o que é necessário para entender o assunto" (idem supra, itálicos nossos). E o que é necessário saber é, primeiramente, o Princípio de Arquimedes ou lei do етрихо:

um sólido mais pesado que um fluido, quando posto nele, desce para o fundo do fluido; e o sólido pesado no fluido será mais leve que seu verdadeiro peso [no ar] [de uma quantidade igual ao] peso do fluido deslocado (ARQUIMEDES. Sobre os corpos flutuantes, Livro I, proposição 7 apud LUCIE, 1986, p. 98 - itálico nosso).

Numa linguagem atual: todo corpo mergulhado em um fluido sofre a ação de um empuxo ver- tical, para cima, igual ao peso do líquido deslocado, de modo que o peso do corpo imerso é igual ao seu peso no ar menos o peso, no ar, do volume de fluido que esse corpo deslocou. Galileu, assim, nos propõe:

suspendamos, então, um metal em uma excelente balança e, no outro braço, um contrapeso de mesmo peso no ar que o metal. Se agora mergulharmos o metal na água, deixando o contrapeso no ar, teremos de aproximar este último do fulcro [o ponto fixo entre os braços da balança], a fim de continuar equilibrando o metal (GALILEU, 1986, p. 106).

Explica-se, também, que o peso específico do metal será tantas vezes maior que o da água deslocada quantas vezes a distância inicial entre o contrapeso e o fulcro for maior que essa distância no equilíbrio hidrostático (que é quando aproximamos o contrapeso do fulcro a fim de manter os braços da balança na horizontal). Trata-se agora do chamado princípio da alavanca, ou seja, nas palavras do próprio Galileu em Le mechaniche:

pesos desiguais, suspen- 
sos em distâncias desiguais, pesarão igualmente quando essas distâncias estiverem [em relação ao fulcro] em proporção inversa à de seus pesos (GALILEU. Le mechaniche. Opere, v. 2, 161, apud Lucie, 1986, p. 99).

Desse modo, combinando a lei do empuxo e o princípio da alavanca, é possível, pois, calcular, a partir das diversas posições do contrapeso nos diversos equilíbrios hidrostáticos, os pesos específicos, em relação à água, do ouro, da prata, e da liga composta dos dois na coroa, bem como a exata proporção desses primeiros nesta última.

Algumas implicações desses dois princípios nos são particularmente sugestivas. A lei do empuxo, como nota Lucie, "convence Galileu de que não há corpos pesados em si ou corpos leves em si" (LUCIE, 1986, p. 98), mas sim, dizendo em termos contemporâneos, corpos que, dispondose como corpos imersos ou como meios de imersão, encontram-se em diferentes relações de densidade; relações estas que variam conforme o caso, de modo que, mudada a relação com o meio referencial, um mesmo corpo pode "flutuar" ou "afundar". Consequentemente, "ser pesado" ou "ser leve" não é uma qualidade do corpo tomado em si mesmo. Não há, pois, aquilo que Arquimedes chamava de "o verdadeiro peso" de um corpo. Ora, isso é o contrário do que supunha a física aristotélica, para a qual materiais intrinsecamente pesados, como seria a terra, possuem seu lugar natural embaixo, e por isso tendem a descer, enquanto materiais intrinsecamente leves, como seria o fogo, possuem seu lugar natural em cima e por isso tendem sempre a subir. O sistema aristotélico, ao supor corpos naturalmente leves ou pesados, pressupunha uma ordem cósmica, com seus lugares fixados "em cima" e "embaixo", separando regiões qualitativamente distintas no espaço. Assim, além da já comentada recusa galileana da epistemologia aristotélica, que separava ciência e demiurgia, epistéme e poiésis, essa pequena balança hidrostática, através de um problema que parecia ser meramente técnico (a coroa de Hieron), permite que Galileu, a partir do sentido especulativo que ele extraiu do princípio de Arquimedes, recuse, juntamente com a epistemologia de Aristóteles, também sua cosmologia, composta de diferentes lugares naturais para objetos feitos de diferentes materiais.

Mas esse sentido especulativo do princípio de Arquimedes ajuda, além disso, a compreender 
melhor a própria epistemologia galileana. Com efeito, não se trata de dizer que o "ser pesado" e o "ser leve" sejam considerados por Galileu como qualidades secundárias, que são aspectos que parecem pertencer aos objetos mas são, na realidade, os efeitos que o objeto produz em um sujeito percipiente, como as cores, os odores, os sabores, etc., que não estão nas próprias coisas mais do que a dor ou a cócega estão na agulha que nos fere ou na pluma que nos toca (Cf. GALILEU, 2013). Entre as qualidades primárias de um corpo, isto é, entre as coisas que são necessariamente pensadas ao ser concebida uma substância corpórea em geral, encontra-se, por exemplo, o "mover-se" e o "estar parado" (idem, ibidem), os quais sabemos, por outro lado, que, para Galileu, também não eram propriedades absolutas, mas estados que se determinam num sistema de relações 4 . Também nos parece ser este o estatuto do pesado e do leve. No caso da gravidade dos corpos, assim como no estatuto do movimento, temos algo que nem está objetivamente na coisa tomada em si mesma e isoladamente, como alguma sua qualidade intrínseca, nem está em nós, como se fosse mera aparência subjetiva: o movimento e a gravidade são reais e não fenomênicos, mas não são realidades absolutas. Isso mostra, com efeito, que a separação entre qualidades primárias matematicamente apreensíveis e qualidades secundárias sensíveis não é suficiente para atribuir a Galileu uma ontologia de caráter platônico, que afirmaria o real como essências absolutas, ocultas por trás das aparências. As qualidades primárias nos parecem, antes, algo que seria imanente ao mundo justamente na medida em que existem no interior de um sistema de relações. Em linguagem anacrônica diríamos, talvez, que segundo as articulações entre a epistemologia e a ontologia de Galileu, não conhecemos tais essências, mas sim estruturas:

[Galileu] mantém-se dentro da perspectiva realista, pois a estrutura do universo é dada objetivamente e cabe ao homem apenas desvendar parte dessa estrutura. Esse des-

\footnotetext{
${ }^{4}$ Abstemo-nos de explicar a superação galileana da oposição ontológica afirmada por Aristóteles entre movimento e repouso, bem como toda a concepção de Galileu sobre as condições de operatividade (mecânica e/ou ótica) do movimento, pois julgamos que isso excederia demasiadamente nosso tema. Limitamo-nos a sugerir que a retirada do movimento e da gravidade da condição de realidades isoladas mas, por outro lado, sua qualificação como qualidades primárias, isto é, como propriedades reais, tende a indicar que a própria natureza, para Galileu, é precisamente um sistema de relações: seu relativismo não é uma negação da realidade dos eventos naturais por ele visados.
} 
vendamento se faz através de demonstrações necessárias cujo o protótipo é precisamente a Geometria (NASCIMENTO, 1986, p. 58 , itálicos nossos).

Ao mostrar que "ser pesado" e "ser leve" é algo derivado de um sistema de relações e, mais ainda, ao mostrá-lo justamente produzindo esse sistema sob a forma de um instrumento material real $\mathrm{e}$ indicando a possibilidade de, com ele, calcular tais relações, Galileu nos permite pensar os instrumentos não como algo que o homem usa como um reles meio de representar a natureza distante. Em vez de um sustentáculo matemático extrínseco, acoplado desde fora à natureza, os instrumentos científicos galileanos parecem ser, antes, partes da natureza.

Assim, aproveitando uma segunda consideração especulativa dos princípios empregados na $b i$ lancetta, poderíamos fazer um uso alegórico do princípio da alavanca para responder, por exemplo, a Descartes, que o ponto fixo arquimediano procurado nas Meditações, o fundamento para a ciência e que ele julgava encontrar apenas no cogito, Galileu o encontra na possibilidade de fixar, sob a forma de um instrumento, as relações matemáticas operantes no seio da natureza. Diría- mos também, ainda nesse registro alegórico, que a própria configuração de uma balança sugere, de modo privilegiado, a noção de estrutura que empregamos acima para indicar a concepção de conhecimento envolvida nos instrumentos galileanos: é apenas na relação entre dois objetos colocados nos pratos da balança que tais objetos se definem reciprocamente quanto àquilo que se procura medir, isto é, no caso, os pesos. Os objetos não podem, pois, ser tomados separadamente ou fora do instrumento capaz de coordenálos: o instrumento, como estamos tentando sugerir, deve ser, pois, a própria existência material de uma lei ou princípio pelo qual a natureza age. Acrescentamos, ademais, que, etimologicamente, tanto a palavra instrumento quanto a palavra estrutura derivam do mesmo verbo, struo, cujo sentido não é outro senão o de: arranjar, dispor ordenadamente (e.g. as tropas militares ou as palavras numa frase), mas também construir, produzir, ou ainda arquitetar, maquinar, planejar. Ora, neste único verbo já se conjugam a mutabilidade das ações e gerações e a estabilidade da consistência interna; o aspecto poiético da construção e o epistêmico da ordem e da inteligibilidade.

Vale lembrarmos também, a tí- 
tulo de breve exemplo, algumas passagens dos Discorsi circunjacentes à demonstração do princípio do movimento uniformemente acelerado: depois que Simplício, o aristotélico, diz que "teria sido oportuno apresentar neste lugar alguma experiência...", Salviati, o galileano, responde:

Vós, como verdadeiro cientista, fazeis pedido muito razoável, [...] e assim convém nas ciências que aplicam às conclusões naturais as demonstrações matemáticas, [...e e] confirmam com experiências sensiveis os seus principios que são o fundamento de toda a estrutura subsequente. (GALILEU, 1988, p. 174 e ss - itálicos nossos).

E a própria teoria galileana - exposta previamente sob a forma de definições, axiomas, teoremas, proposições etc. - é, então, descrita como uma "...imensa máquina de infinitas conclusões..." (idem, ibidem). Ora, das citações supra decorre que os princípios, que, por um lado, já haviam sido formulados de acordo com toda a parte teórica precedente da terceira jornada dos Discorsi, seriam, por outro lado, inconfirmáveis e virtualmente externos à natureza das coisas se não fosse feita essa aplicação - a qual há de ser, portanto, coisa muito diferente da aplicação instrumentalista que não se comprometia com o valor de verdade das teorias (Cf. NASCIMENTO, 1996). E se nos dois casos - por exemplo, em Osiander e em Galileu - as teorias mesmas podem ser de algum modo chamadas de instrumentos, a profunda diferença entre suas concepções de conhecimento deve residir precisamente no que se pode considerar como instrumento nos dois casos: em Osiander trata-se de meros instrumentos de cálculo, em Galileu, trata-se de uma máquina teórica de conclusões verdadeiras, que se prolonga em máquinas mentais, tais como, no caso dos Discorsi, o dispositivo do plano inclinado, mas também, como pretendemos haver mostrado aqui, em máquinas materiais, tais como a bilancetta e o compasso geométrico e militar.

\section{3 - O Telescópio}

Resta, portanto, que nos encaminhemos ao telescópio. Tentar encontrar, nesse instrumento particularmente, os traços da união entre especulação filosófica e produção técnica que viemos apontando nos demais, será algo bastante significativo, visto que, dife- 
rentemente do compasso e da balança, ligados diretamente à tradição pitagórica e arquimediana, o telescópio foi construído de um modo bastante peculiar, envolvendo controvérsias desde a época mesma de Galileu. A controvérsia histórica diz respeito ao fato de que Galileu não foi o inventor da ideia do telescópio, tendo sabido de sua existência por meio de relatos de amigos numa viagem a Veneza, em 1609, mas havendo, segundo alguns de seus contemporâneos, feito do telescópio um "filho" seu. Já uma outra controvérsia, epistemológica, diz respeito à questão de saber se Galileu produziu o telescópio procedendo dentro dos cânones racionalistas, isto é, partindo de premissas teóricas gerais e delas deduzindo necessariamente consequências particulares, ou valendo-se de um procedimento eminentemente empírico, ou seja, por tentativa e erro. Nossa leitura, que pretende mostrar, não a perfeita conformidade da produção deste instrumento com as demais, mas sim uma mesma compreensão geral sobre a relação entre racionalidade e técnica, procurará justamente coordenar as duas controvérsias, a histórica e a epistemológica.

Em Sidereus Nuncius, Galileu escreve:
Há cerca de dez meses chegou aos meus ouvidos a notícia que certo belga tinha construído um pequeno telescópio por meio do qual objetos visíveis, embora muito distantes dos olhos do observador, eram vistos claramente como se estivessem perto. Desse efeito, verdadeiramente notável, várias experiências foram relatadas, às quais algumas pessoas davam crédito enquanto outras recusavam. Uns poucos dias mais tarde a notícia me foi confirmada [...] o que me motivou a dedicar-me sinceramente à investigação do meio pelo qual eu podia chegar à invenção de um instrumento similar, o que consegui pouco depois baseando-me na doutrina das refrações (GALILEU, Sidereus Nuncius, apud ÉVORA, 1994, p. 37, itálicos nossos).

Todavia, Fátima Évora (1994, Caps. 2 e 3) mostra-nos que a julgar, seja pelos procedimentos apresentados pelo próprio Galileu, seja pelas teorias óticas a que Galileu poderia ter tido acesso a afirmação de que o instrumento foi produzido com bases na dou- 
trina da refração deve ser tomada como deveras problemática! ${ }^{5}$ A argumentação teórica minuciosa e a ampla investigação documental de Fátima Évora nos é completamente persuasiva e sua conclusão se nos impõe de modo inelutável:
A descoberta de Galileu do telescópio nem foi obra do acaso, nem simples re- produção de um disposi- tivo cuja as partes e dis- posições se conhecia pre- viamente. Porém também não foi feita a partir de um raciocínio lógico de- dutivo [...]. Galileu conse- guiu o progresso graças a tentativa e erro" (ÉVORA, 1994, p. 81).

Resta-nos, porém, refletir um pouco sobre o que poderiam significar para nosso cientista-filósofo essas investidas concretas e tateantes que ele realizou - certamente sem seguir nenhum a priori, ou melhor, nenhum a priori particular sobre ótica e produção de imagens através de lentes. O que seria afinal isso que se encontra entre o raciocínio lógico dedutivo e puro acaso, sem se confundir com ambos? É para tentar responder a essas perguntas que atentamos às controvérsias históricas sobre a autoria do instrumento.

Respondendo em Il Saggiatore à acusação de plágio feita por Sarsi, Galileu escreve que, visto que já avisara, no Sidereus Nuncius, ter sabido da existência do telescópio antecipadamente, restaria somente explicar que espécie de auxílio podia lhe ter representado esse conhecimento prévio. Reconhecendo que sem essa informação talvez não houvesse se quer pensado no assunto e tentado construir o aparelho, Galileu, no entanto, adverte:

...que tal notícia tenha facilitado invenção, não creio; e digo mais, que encontrar a solução de um problema marcado e nomeado é obra de muito maior engenho do que aquela necessária para encontrar a [solução] de um problema ainda não pensado nem nomeado, pois neste caso pode haver grandíssima influência do acaso, mas naquele é tudo obra do argumento (dis-

\footnotetext{
5 “... os estudos existentes no século XVI e começo do século XVII sobre a formação de imagens em lentes ou sistemas de lentes não ofereciam bases para a construção do telescópio, com exceção, talvez, do Ad Vitellionem Paralipomena, quibus Astronomia pars Optica Traditur, de Kepler (1604, Frankfurt), o qual Galileu, até outubro de 1610, não havia conseguido ler" (ÉVORA, 1994, p. 43).
} 
corso) (GALILEU, Sidereus

Nuncius, apud ÉVORA, 1994, p. 44-45 - itálicos nossos).

O que temos aqui? Mais uma alegação da qual devemos suspeitar? Talvez não. Afinal, o que Galileu nos diz é que a certeza da existência do instrumento afasta o acaso e torna a situação um problema para o engenho do cientista. Não era uma hipótese a ser testada empiricamente: era uma certeza que a construção do telescópio era possível; afinal, ela era um fato, ela era real ... e o que é real deve poder ser demonstrado com base na ciência 6 . Este seria o a priori de Galileu, um a priori geral que nada tem de platônico, de idealista ou de solipsista, porque, muito pelo contrário, diz respeito à inteligibilidade dos eventos empíricos considerados em seu âmbito próprio.

Não poderia ser essa uma explicação mais justa para com o ilustre filósofo e matemático do que a que supõe que estaria mentindo para garantir a legitimidade científica do seu equipamento ao dizer que fundava-se na doutrina da refração? Ora, já poderíamos, com efeito, perceber estas mesmas ideias, que julgamos encontrar no II Saggiatore, quando, no Sidereus Nuncius, Galileu dizia que, dedicou-se sinceramente à investigação e que só o fez depois que a notícia foi confirmada e não enquanto algumas pessoas davam crédito é experiência mas outras não. Talvez nessa sinceridade algo insuspeitado se encontre: não estando as fontes de Galileu a inventar ficções fabulosas sobre um maravilhoso instrumento, a existência do telescópio passa a ser, pois, de direito, matéria da ciência; e o procedimento tateante, o correr sucessivo das tentativas de alguém que, no entanto, sabe com certeza que é realizável seu projeto, bem poderia constituir uma das conotações da expressão discorso. Se a existência do telescópio não era uma fantasia como os eventos narrados nas obras dos literatos, então a empreitada de Galileu para produzir o instrumento, ainda que de modo tateante, era tarefa a exigir-lhe engenho e argumento; e ao senhor Sarsi, que lhe acusava de plágio, também nesse contexto Galileu poderia dizer: Sr. Sarsi, a coisa não é assim! Porque um telescópio existia, tentativa e erro para encontrá-lo já não era

\footnotetext{
${ }^{6}$ Não se deve entender aqui o contrário do que já disséramos, a saber, que Galileu recusa o conhecimento de essências: "O que é acessível ao conhecimento científico são os acidentes, as propriedades ou sintomas. Estes, à medida que revelam o real, são os acidentes primários, isto é, o que pode ser tratado geometricamente" (NASCIMENTO, 1986, p. 57). É preciso simplesmente que não esqueçamos que estes acidentes são "acidentes primários e reais" (Galileu, 2013, p. 13).
} 
vaguear inutilmente num escuro labirinto.

\section{Conclusão}

\section{(...) A filosofia está escrita} neste grandíssimo livro que aí está aberto continuamente diante dos olhos (isto é, o universo), mas não se pode entendê-lo se primeiro não se aprende a entender a língua e conhecer os caracteres nos quais está escrito. Ele está escrito em língua matemática, e os caracteres são triângulos, círculos e outras figuras geométricas, meios sem os quais é humanamente impossível entender-lhe sequer uma palavra; sem estes tratase de um inútil vaguear por um obscuro labirinto (...) (GALILEU, Il Saggiatore $\S 6$ apud MOSCHETTI, 2013, p. 56)

Quando Galileu diz, na supracitada frase do parágrafo 6 de Il Saggiatore (Cf. MOSCHETTI, 2013), que o universo está escrito em língua matemática, revela que o logos encarna-se no seu tatear e no instrumento assim encontrado: a ciência não está fundada nos livros escritos pelos homens nem no elucubrar subjetivo, está fundada nas coisas77. Assim, é possível a um cientista, "após haver cuidadosamente revisto o que Arquimedes demonstra em seus tratados" (GALILEU, 1986 p. 105) ir em direção da natureza e produzir uma balança hidrostática; mas também, em contrapartida, sabendo que existe um telescópio, colocar-se a produzi-lo, consciente de que está lidando, na prática, com a doutrina da refração - a ser escrita, talvez com mais perfeição do que, no momento, podia sê-lo por suas mãos, num outro tratado pelas mãos de um outro cientista.

Já se pode, portanto, compreender quão significativa é esta caracterização dos instrumentos para a mudança na concepção geral acerca da ciência. Por tudo que dissemos, parece não estarmos muito enganados se reconhecermos em tais instrumentos a síntese entre a instrumentação - que valoriza o trabalho empírico e a tentativa de dar conta dos fenômenos particulares - e a postura ativa do homem diante da natureza, que valoriza o re-

\footnotetext{
${ }^{7}$ Confira-se também, em Moschetti, 2013, pp. 92ss, especialmente o trecho: “A famosa frase de Galileu parece enunciar um princípio não apenas metodológico mas também ontológico: assim deve ser a física porque a matéria é ela mesma estruturada geometricamente". Tal leitura confirma, por assim dizer, o que nós, aqui, estamos apresentando quase como uma "revanche" moderna da ontologia pitagórica.
} 
torno ao próprio intelecto para encontrar os princípios do conhecimento. Os princípios da matemática são os princípios da natureza; qualquer transcendência de estilo platônico é aqui excluída.

Para salientar apenas uma das implicações dessa investigação para a compreensão do pensamento de Galileu e da própria Revolução científica dos séculos XVI e XVII, cabe salientar que ela incide diretamente na - já um tanto envelhecida - polêmica entre Alexandre Koyré e Stillman Drake, reportada e resumida por THUIILER (1994), no capítulo cujo título enuncia a pergunta ao redor da qual polemizaram os dois primeiros comentadores: "fez Galileu experiências?". A resposta de Koyré é negativa, ao passo que a de Drake é afirmativa. Drake, analisando, por exemplo, anotações manuscritas de Galileu, tenta demonstrar que elas seriam medições de dados concretos recolhidos em efetivos experimentos (THUIILER, 1994, p. 130). Koyré, sublinhando, entre outras coisas, a impossibilidade de medições suficientemente precisas, bem como um possível fundo platônico para o estabelecimento das teorias galileanas, procura provar que esse estabelecimento em nada dependeu de experimentos concretos, os quais, portanto, poderiam não haver sequer existido, reduzindo- se, aqueles experimentos descritos nos livros de Galileu, a meros expedientes de pensamento. Assim, se, por um lado, não aceitamos completamente a tese de Koyré - de que Galileu não fez concretamente seus experimentos - por julgá-la, não como sendo falsa, mas como sendo difícil de ser demonstrada, por outro lado, queremos crer que mesmo que Galileu tenha efetivamente feito experimentos, algo da concepção básica de Koyré - ao menos naquilo que concerne ao caráter essencial da postura ativa da ciência galileana - pode ser mantido se atentarmos à maneira pela qual os instrumentos são pensados por Galileu. Se não é certo que experimentos existiram, não se pode dizer o mesmo dos instrumentos. Assim, repetindo a questão que se encontra no título do capítulo de Thuillier — "fez Galileu experiências?" - poderemos arriscar uma conclusão dizendo: não sabemos, mas sabemos que, em sua oficina, ele construiu realmente inúmeros instrumentos, como o compasso geométrico militar, a balança hidrostática e o telescópio. E tais instrumentos são, eles próprios, as concretizações materiais de certas leis da natureza, legíveis apenas matematicamente. Não se tratam de armaduras extrínsecas ou armadilhas para capturar e aprisionar os da- 
dos observacionais em uma reles "regra de cálculo", mas uma real articulação inteligível no seio da natureza sensível.

Ora, não é pouco o que fica posto em jogo: trata-se, naquele momento histórico de fundação de um novo modo de pensar, "de uma determinada imagem $d a c i$ ência, uma determinada maneira de interpretar o trabalho científico" (THUIILER, 1994, p. 117). Hoje, em 2019 - quando a política científica brasileira exibe uma imagem da ciência que a recoloca na servil posição de técnica solucionadora de problemas práticos (especialmente daqueles necessários à indústria e ao mercado de ser- viços) sem potência para questionar o poder teológico-político que, por não haver sido superado mas tão somente recalcado, calamitosamente retorna com tal reedição do programa instrumentalista é imperioso, portanto, diferenciar a despotencializadora instrumentalização da ciência, limitada a salvar as aparências, de sua desejável instrumentação. Esta última, com seus instrumentos simultaneamente corporais e intelectuais, recoloca um brado que, pensávamos, havia sofrido sua obsolescência junto com as promessas não cumpridas do iluminismo, mas que mostra hoje sua renovada importância: Sapere Aude!

\section{Referências}

ARISTÓTELES. Éthique de Nicomaque. Paris: Garnier, 1948.

CLAVELIN, M. “A revolução galileana: revolução metodológica ou teórica?" in Cadernos de História e Filosofia da Ciência, No. 9, 1986, pp. 33-44.

COPÉRNICO, N. Prefácio de Nicolau Copérnico aos Livros das Revoluções para o Santíssimo Senhor Paulo III, Sumo Pontífice. Trad. Cristiano \& Antônio Rezende. In Cadernos de História e Filosofia da Ciência, Campinas, Série 3, v. 18, n. 1, p. 259-268, jan.-jun. 2008.

ÉVORA, F. A Revolução Copernicano-Galileana, Vol II. Campinas: CLEUnicamp, 1994.

FRIEDMAN, M. "Descartes e Galileu: copernicanismo e o fundamento metafísico da física" in Broughton, J. \& Carriero, J. (Org.) Descartes. Porto Alegre: Penso, 2011.

GALILEI, G.Ciência e Fé - Org. Trad. e Notas: Carlos Arthur R. Nascimento. São Paulo: Ed. Unesp, 2009. 
GALILEI, G. Duas Novas Ciências. Trad.: Letizio \& Pablo R. Mariconda. São Paulo: Nova Stella, 1988.

GALILEI, G. La Billancetta. - A pequena Balança Hidrostática. In Cadernos de História e Filosofia da Ciência, No. 9, 1986, pp. 105-107.

GALILEI, G.. Le Operazioni del compasso geometrico et militare... Padova: Paolo Frambotto, 1649. Disponível em Gallica. Acessado [em 13 de agosto de 2019].

GALILEI, G. Parágrafo 48 de O Ensaiador (1623). Tradução: M. Moschetti. In Revista Guairacá, Volume 29, n² 2, 2013, p. $211-218$.

KIRK, RAVEN \& SCHFIELD. Os Filósofos pré-socráticos. Lisboa: Calouste Gulbenkian, 1994.

LOPARIC, J. "O ficcionalismo de Osiander: in Cadernos de História e Filosofia da Ciência, Campinas, Série 3, v. 18, n. 1, jan.-jun. 2008, p. 227-251.

LUCIE, P. "Galileu e a tradição arquimediana" in Cadernos de História e Filosofia da Ciência, No. 9, 1986, pp. 95-104.

MOSCHETTI, M. "Matéria e Geometria n'O Ensaidor". Revista Guairacá, Volume $29 \mathrm{n}^{\circ} 2$ - 2013.

NASCIMENTO, C. A. R. De Tomás de Aquino a Galileu. Campinas: IFCHUnicamp, 1996.

NASCIMENTO, C. A. R. "Sobre uma frase de Galileu" in Cadernos de História e Filosofia da Ciência, No. 9, 1986, pp. 53-59.

OSIANDER, A. Sobre as Hipóteses desta Obra (prefácio ao De Revolutionibus Orbium Coelestium, de Nicolau Copérnico). Trad. Introd. e Notas de Zeljko Loparic. In Cadernos de História e Filosofia da Ciência, No. 1, 1980, pp 44-61.

POPPER, K. Conjecturas e Refutações. Brasília: UnB, 1982.

THUILLIER, P. De Arquimedes a Einstein. São Paulo: Zahar, 1994.

Recebido: 04/07/2019

Aprovado: 09/11/2019

Publicado: 17/11/2019 
